\title{
Fundamentals, Representative Applications and Future Perspectives of Green Chemistry: A Short Review
}

\author{
Kalyan Kumar Rana ${ }^{*}$, Suparna Rana ${ }^{2}$ \\ ${ }^{1}$ Department of Chemistry, Gushkara Mahavidyalaya, Gushkara, Burdwan, WB, India \\ ${ }^{2}$ Department of Applied Science, Haldia Institute of Technology, Haldia, WB, India \\ Email: kalyankrana@yahoo.co.in, ranamandal@yahoo.co.in
}

Received 29 May 2014; revised 9 July 2014; accepted 19 August 2014

Copyright (C) 2014 by authors and OALib.

This work is licensed under the Creative Commons Attribution International License (CC BY). http://creativecommons.org/licenses/by/4.0/

(c) (i) Open Access

\section{Abstract}

Green chemistry is an eco-friendly and rapid emerging field of chemistry which offers a green alternative to conventional chemistry practices. It focuses on the reduction, recycling and removal of the use of toxic and hazardous chemicals through innovative alternative routes making desired products with minimum environment impact. Its growing importance is in exploitation of maximum possible resources in such a way that, there is minimum production of undesired chemical wastes. It is helpful to chemists and chemical engineers in research, development and production for improvement of more eco-friendly and efficient products which may also have significant financial benefits. The green chemistry movement is part of a larger movement that leads to sustainable development, sustainable economics and sustainable living practices. Sustainable chemistry is a scientific concept that seeks to improve the efficiency with which natural resources are used to meet human needs for chemical products and services. It encompasses the design, manufacture and use of efficient, effective, safe and more environmentally benign chemical products and processes. This has enormous potential to contribute in renewable energy technologies, synthesis of new molecules and development of pollution prevention technologies. The aim of this review is to raise awareness on the fundamental aspects, necessities and benefits of green chemistry.

\section{Keywords}

Green Chemistry, Sustainable Development, Renewable Feedstock, Atom Economy, Hazardous Chemicals, Biodegradation

Subject Areas: Environmental Chemistry, Green Chemistry, Organic Chemistry

${ }^{*}$ Corresponding author. 


\section{What Is Green Chemistry?}

"Green chemistry" is essentially a way of thinking rather than a new branch of chemistry and is about utilizing a set of principles that seek to reduce the environmental impact of chemical processes and products. The term green chemistry, also known as clean or benign or sustainable chemistry, refers to the design of chemicals and formulation of processes that reduce the risk to humans and minimize environment pollution. The goal of green chemistry solutions is to lessen or eliminate hazardous impacts of chemicals over a chemical product's life-cycle. Key guidelines associated with green chemistry are outlined in the US Environmental Protection Agency's “Twelve Principles of Green Chemistry”, which serve as the basis of this novel set of ideas.

\section{Why Green Chemistry?}

There is no doubt that our lives have been enhanced by chemistry. That is something chemists and chemistry learners need to celebrate. However, environmental problems such as biomagnification of DDT, ozone layer depletion, the Cuyahoga River calamity (caught fire in 1969, mobilized the nation, made basis for passage of the US Clean Water Act in 1972), the Love Canal tragedy (neighborhood of Niagara Falls, New York, used to conceal over 21,000 tons of toxic wastes in 1950's by the then Hooker Chemical Company, caused a public health disaster and an urban planning disgrace in 1978), the Bhopal disaster (world's worst industrial disaster, occurred on the night of 2-3 December 1984 at the Union Carbide India Limited pesticide plant, almost 20,000 people died), the Chernobyl disaster (catastrophic nuclear explosion occurred on 26 April 1986 at the Chernobyl Nuclear Power Plant, Ukraine, USSR) and the latest Fukushima Nuclear Power Plant tragedy (meltdown of three of the plant's six nuclear reactors, when hit by the tsunami triggered by the Tōhoku earthquake on 11 March 2011) are all too familiar examples of chemistry gone wrong. In responding to the growing concern, governments introduced regulations to limit pollution and exposure to hazardous chemicals. Green chemistry represents a fundamental shift from this model toward a pollution avoidance paradigm. Its premise is that a chemically benign process and substance presents no risk.

\subsection{The Backdrops}

Rachel Louise Carson (1907-1964), an American marine biologist, conservationist and nature writer, wrote the landmark scientific book Silent Spring in 1962 (Pub. Houghton Mifflin, US) about the ill effects of synthetic pesticides that brought environmental issues to the attention of the American public and later, the world. This book showed the way to a nationwide environmental movement that ultimately led to the foundation of US Environmental Protection Agency (EPA) in 1969. Its goal was to prepare and maintain conditions under which man and nature can coexist in productive harmony. The EPA's first notable decision was to ban the use of DDT and other chemical pesticides.

Until 1980s, the chemical industry and the EPA were focused mainly on pollution clean-up, but a major characteristic shift began to occur among chemists. Scientists, who came of age during the decades of growing environmental awareness, started to find avenues of preventing pollution in the first place. The Organization for Economic Co-operation and Development (OECD), an international association of over 30 industrialized countries, held meetings through the 1980s addressing environmental concerns. They made a series of international recommendations which focused on a co-operative change in existing chemical processes and pollution prevention [1].

- In 1993 the Interuniversity National Consortium-Chemistry for Environment [2]. (INCA Consortium; Italy) was established by 5 founder member universities. INCA's ongoing mission is to gather, coordinate, and integrate the research activities of its member academic groups. One of INCA's focus areas is pollution prevention through research for cleaner reactions, products and processes.

- In August 1996, IUPAC approved the foundation of a Working Party on Synthetic Pathways and Processes in Green Chemistry following their rules and regulations [3]. The aim of this subcommittee is to develop actions devoted to the cause of green chemistry and for its wider benefit towards the future of chemistry and society as whole.

- Also in 1997, the ACS Green Chemistry Institute (GCI), a non-profit organization was established [4], with the mission to enable, catalyze and implement green chemistry and green engineering ideas throughout the global chemical enterprise. Also its main focus was to promote green chemistry by facilitating industrygovernment partnerships with universities and national laboratories to develop economically sustainable 
clean-production technologies. In 2001, the Green Chemistry Institute became a part of the American Chemical Society, the largest professional scientific society and membership organization for chemists in the world. The two organizations coupled to pursue their joint interests in the discovery and design of chemical products and processes that eliminate generation and use of hazardous materials.

- In 1998 upon EPA proposal, the OECD formed a directive committee for the development of chemistry practices which initiated a program called "sustainable chemistry" aimed at pollution prevention and better industrial performance [5]. USA and Japan were appointed co-leaders in the field of research and development while Italy was appointed leader of the Educational Act. Paul T. Anastas and John C. Warner of USEPA co-authored the groundbreaking book, Green Chemistry: Theory and Practice (Oxford Univ. Press) in 1998. The famous " 12 Principles of Green Chemistry' outlined in this book illustrates a basic philosophy that motivated governments, scientists and industries at the time and still continues to guide the green chemistry movement. The first books and journals on the subject of green chemistry were introduced in the nineties that include Green Chemistry (Royal Society of Chemistry, 1999), one of the most popular journals of this category.

The Nobel Prizes in Chemistry were won for research in the areas of chemistry that were largely seen as being green chemistry in both 2001 (WS Knowles, R Noyori and KB Sharpless) and 2005 (Y Chauvin, RH Grubbs and RR Schrock). These Nobel Prizes reinforced the importance of research in green chemistry and helped create an improved awareness among scientists and administrators. In this decade, a number of chemistry associations and institutes were established, several journals were launched, lots of valuable books were written and numerous conferences were held all over the world whose prime importance were to uplift the standard and open newer avenues of green chemistry.

\subsection{The Famous 12 Principles of Green Chemistry}

Green chemistry is commonly presented as a set of twelve principles proposed by P. T. Anastas and J. C. Warner [6] [7]. The principles comprise instructions for mainly professional chemists to implement new chemical compounds, new routes of syntheses and new environmentally benign technologies. The first principle describes the basic idea of green chemistry, protecting the environment from pollution. The remaining principles are focused on several vital issues like atom economy, toxicity, choice of solvent, consumption of energy, use of raw materials from renewable resources and degradation of chemical products to nontoxic substances that are friendly for our environment.

In short, the 12 principles for green chemistry are:

1) Prevention: It is better to prevent waste than to treat or clean up waste after it is formed. This is a fundamental principle. Several thoughts among scientists developed in the last decades can be changed dramatically by the preventative action. Most of the chemical processes and synthetic routes followed today produce plenty of wastes and toxic secondary substances. Green chemistry can prevent these by-products by redesigning the feedstocks and the chemical processes in advance and with inventive alteration. It recalls the old proverb "an ounce of prevention is worth a pound of cure". For example, solventless reaction technique can be a good effort in this regard [6].

2) Maximize synthetic methods, Atom Economy: Synthetic methods should be designed to maximize the incorporation of all materials used in the process into the final product. Almost all synthetic methods until now are wasteful and their yields are between, on an average, 70\% - 90\%. Green chemistry supports that synthetic routes can be directed towards maximizing the incorporation of all substrates employed in the chemical process into the final product, eliminating the need to recycle unwanted by-products. Atom economy is a method of expressing how efficiently a particular reaction makes use of the reactant atoms [8]. This principle gets into the actual chemistry of how products are made. We know, atoms are assembled to make molecules and the molecules come together to make materials. According to this principle it is best to use all the atoms in a process. The atom economy is a simple calculation that can be expressed as A.E. = Formula Weight (FW) of Product divided by the FW of all of the reactants. A well known example is hydrogenation of carboxylic acids to aldehydes using solid catalysts.

3) Less Hazardous Chemical Synthesis: Whenever practicable, synthetic methodologies should be designed to use and generate substances that possess little or no toxicity to human health and the environment. Green chemistry approach makes every effort, wherever practical, to design safer synthetic schemes which deal with less toxic starting materials as well as the products of the synthesis. Handling of less toxic materials means less pol- 
lution to the environment as well as less hazards to the workers in industries and research laboratories. This principle is focused on how we make molecules and materials. The goal is to reduce the hazards of the chemicals that are used to make a product (solvents, reagents etc.). Throughout the history of evolution and development of chemical sciences, chemists have traditionally not serious about the health impacts of the chemicals they are using and the hazards that are associated with them. Traditionally they have used whatever means necessary. Today green chemistry initiatives have established that less hazardous reagents and chemicals can be used in a process to make desired products and many times they are made in a more efficient manner. For example, adipic acid synthesis by oxidation of cyclohexene using hydrogen peroxide [9].

4) Designing Safer Chemicals: Designing must become a fundamental aim of green chemists to affect the desired function and properties of the chemical product while minimizing their toxicity to human and the environment. Presently, there are around 100,000 recognized chemical substances in the market. Most of these substances have been characterized according to their physicochemical properties and toxicities, but there is lack of ecotoxicological data for most of them. Commencing for 1980s, many countries have introduced and reformed stringent regulations from time to time and new chemicals are monitored more effectively. To be specific, pesticides are a class of compounds which are designed to be toxic to the pests but non-toxic to the surrounding wildlife and ecosystem. For example new and less hazardous bio-based pesticide Spinosad [10].

5) Safer Solvents and Auxiliaries: Use of auxiliary substances viz., solvents, separating agents etc. should be made unnecessary wherever possible and innocuous when used. Most of the chemical reactions are performed in a solvent or a mixture of them. A large number of organic solvents are volatile (VOC's) in nature and subsequently pose a threat to the environment and highly dangerous to humans. This principle focuses on creating products in such a way that they use less hazardous solvents. For example supercritical fluid extractions, syntheses in ionic liquids etc. [11].

6) Design for Energy Efficiency: Energy requirements should be acknowledged with respect to their environmental and economic impacts and should be minimized. As far as practicable, synthetic methods should be conducted at ambient temperature and pressure. Today there is a focus on renewable energy and energy conservations. Energy is mainly used for transportation purposes and to provide electricity to our homes, businesses and industries. It is established that traditional methods for generating energy contribute to global environmental problems and plays important role in determining costs of the products [12]. This principle focuses on creating products and materials in a highly efficient manner so that associated pollution and costs are minimized.

7) Use of Renewable Feedstocks: A raw material or feedstock should be renewable rather than deplete whenever technically and economically practical. Starting raw material for synthetic processes as well as most of the products we use in our everyday life are mostly petrochemical products. This principle seeks to shift our dependence on petroleum and to make products from renewable materials that can be collected or produced locally. Biodiesel is one example of this where researchers are trying to find alternative fuels that can be used for transportation. Other examples include bio-based plastics (polylactic acid), made from renewable feedstocks such as corn and potato wastes, eco-friendly surfactants etc. [13].

8) Reduce Derivatives: Unnecessary derivatizations (e.g., blocking group, protection/deprotection, temporary modification of physical/chemical processes) should be avoided whenever possible. This principle is perhaps the most abstract principle for a non-chemist. The methods that chemists use to make products are sometimes highly complicated and many involve preparation of derivatives of the intermediate products in order to shape the molecules into what they want them to look like. These derivatizations use additional reagents, are wasteful and produce large amounts of by-products. This principle aims to simplify the chemical processes and to look at natural systems in order to design products in a simplified manner. For example, application of on-fiber derivatization to the analysis of volatile carbonyl compounds (VOCs) [14].

9) Catalysis: Catalytic reagents, as selective as possible, are superior to stoichiometric reagents. In a chemical process catalysts are used in order to reduce energy requirements and to make reactions happen more efficiently. Another benefit of using a catalyst is that generally small amounts are required to have an effect. And, if the catalyst is truly a "green" catalyst, it will have little to no toxicity and it will be able to be used over-and-over again in the process. Enzymes are wonderful examples of catalysts that have been proven to perform amazing chemistry. Catalytic reagents with great selectivity can be superior to stoichiometric reagents. Development of new catalysts and more emphasis on catalytic processes are the future of green chemistry techniques. For example efficient $\mathrm{Au}(\mathrm{III})$-catalyzed synthesis of $\beta$-enaminones from 1,3-dicarbonyl compounds and amines [15].

10) Design for Degradation: Chemical products should be designed so that at the end of their function they do 
not persist in the environment and instead break down into innocuous degradation products. Most chemical products and today's consumer items do not degrade easily, thus causing massive environmental problems. Green Chemistry aims at designing products so that at the end of their useful life they break down into innocuous materials. Plastics, for example, do not degrade in our landfills and pharmaceutical drugs, pesticides etc. build up in our environment and animal bodies. This principle seeks to design products in such a way so that they perform their intended function and then, when they are disposed of, will degrade into safe, harmless byproducts. For example, synthesis of biodegradable polymers are gaining widespread acceptance for their various ecological benefits [16].

11) Real-time Analysis for Pollution Prevention: Analytical methodologies need to be further developed to allow for real-time in-process monitoring and control prior to the formation of hazardous substances. Most chemists are familiar with laboratory analysis from their undergraduate training. But analysis can also be performed off-line, at-line, on-line or in-line in a chemical plant [17] a subdiscipline known as process analytical chemistry [18]. Such analysis can detect changes in process temperature, pressure, $\mathrm{pH}$ etc. prior to a reaction going out of control, poisoning of catalysts and other deleterious events before a major incident occurs. For example, use of on-line analyzers for waste water monitoring [19].

12) Inherently Safer Chemistry for Accident Prevention: Substance and the form of a substance used in a chemical process should be chosen so as to minimize the potential for chemical accidents, including releases, explosions and fires [20]-[22]. This principle focuses on safety for the worker and the surrounding community where an industry resides. It is better to use materials and chemicals that will not explode, light on fire, ignite in air, etc. when making a product. For example, dimethyl carbonate is an environmentally friendly substitute for dimethyl sulphate or dimethyl halides for methylation reactions [23] [24].

\subsection{From Research to Practice}

Chemists from all over the world are applying their creative and innovative skills and ideas to develop new processes, synthetic methodologies, environmentally benign reaction conditions and catalysts under green chemistry conception. Commercial applications of green chemistry have led to novel academic research to examine alternatives to the existing synthetic methods. Some of the new developments which have been materialized under green chemistry provisions in recent past are:

- The use of phosgene $\left(\mathrm{COCl}_{2}\right)$ and methylene chloride $\left(\mathrm{CH}_{2} \mathrm{Cl}_{2}\right)$ in the synthesis of polycarbonates has been replaced by fairly gentle diphenylcarbonate [25] [26].

- One of the most polluting reactions in industry is oxidation. Implementation of green chemistry has led to the use of comparatively less polluting reagents e.g., metal ion contamination is minimized by using molecular $\mathrm{O}_{2}$ as the primary oxidant and use of extremely high oxidation state transition metal complexes [27] [28].

- A convenient green synthesis of acetaldehyde is by Wacker oxidation of ethylene with $\mathrm{O}_{2}$ in presence of a catalyst, replacing its synthesis by oxidation of ethanol or hydration of acelylene with $\mathrm{H}_{2} \mathrm{SO}_{4}$ [29].

- If we go through the comprehensive list of the highly honored "US Presidential Green Chemistry Challenge Awards" (three awards) staring from 1996 through 2013 [30], we will see that each winner demonstrates a commitment to designing, developing and implementing a green chemical technology that is scientifically innovative, economically feasible and less hazardous to human health and environment. For example, in 1996, The Dow Chemical Co., USA, won (also in 2013) "Greener Reaction Conditions Award" for their $100 \%$ use of relatively environmentally benign carbon dioxide as blowing agent for preparation of polystyrene foams replacing the notorious CFC.

Propylene oxide (PO) is a chemical building block for a variety of products including detergents, polyurethanes, food additives etc. Traditional PO production uses chlorohydrin which leads to formation of several byproducts and wastes. Dow Chemical and BASF (Badische Anilin und Soda Fabrik, in English: Baden Aniline and Soda Factory, headquartered in Ludwigshafen, Germany, one of the largest chemical company in the world) have jointly developed a new greener route to make PO with hydrogen peroxide and propylene that eliminates most of the undesired wastes [31].

AkzoNobel, Netherlands, has developed a readily biodegradable and cost-effective chelating agent GLDA [32] (glutamic acid diacetic acid tetrasodium salt, marketed as "Dissolvine ${ }^{\circledR} G L$ ") produced from natural and sustainable raw materials, with a high solubility over a wide pH range compared to EDTA and NTA (2,2',2'"-nitrilotriacetic acid or 2-[bis(carboxymethyl)amino]acetic acid, $\left.\mathrm{N}\left(\mathrm{CH}_{2} \mathrm{CO}_{2} \mathrm{H}\right)_{3}\right)$. Most appreciably, GLDA is readily biodegradable and replaces phosphate based detergents which diminishes environmental hazard (mainly eutro- 
phication, meaning, excessive accumulation of nutrients in water-body which causes a dense growth of algae, lowers amount of dissolved oxygen suffocating fish and other aquatic life) to a great extent.

- Spinosad [33]-[36] (of Dow AgroSciences, USA) insecticide, based on a compound found in the bacterial species Saccharopolyspora spinosa, is a low-risk pesticide in widespread use on crops. Natular ${ }^{\mathrm{TM}}$ (of Clarke, USA), a spinosad based mosquito larvicide that provides excellent control in aquatic environments is about fifteen times less toxic than the usual organophosphate alternatives [37].

- BIOCANETM (of Swiss Biostadt Limited, formerly Ciba-Geigy), a successful bio-pesticide, based on a naturally occurring fungus Metarhizium anisopliae, is claimed to be particularly effective against greyback canegrub Dermolepida albohirtum (Waterhouse) [38]. Efficient processes have been devised that converts waste biomass into industrial chemicals, fuels and animal feed [39] [40]. Another process converts waste biomass such as municipal bio-waste, sewage sludge, livestock and agricultural residues to useful products, including hydrogen, ethanol, acetic acid etc.

- For mass production of carboxylic acids, improved and efficient fermentation methods are being used [41]. Ethyl lactate, a non-toxic organic solvent is now cost-effectively and eco-friendly prepared from corns. Because of its nontoxic nature, it is widely used in pharmaceutical preparations, food additives etc. [42].

- A new environmentally friendly technology is revealed to recover heavy metals like iron, chromium, manganese, zinc etc. from waste pickle liquor [43]. Pickle liquor, a solution containing strong acids, is used to remove the surface impurities such as stains, inorganic contaminants, rust and scales from ferrous alloys, copper and aluminum alloys etc.

Because of health and environmental toxicity, demand for non-ionic surfactants [44] (e.g., TERGITOL of Dow Chemical Co.) is growing and a new substrate of this kind, alkyl glycoside, obtained from saccharides is now used extensively [45]. Few coconut oil-based cleansing liquids have also been developed in this connection.

- Feedstock recycling of plastic/polymer wastes into valuable chemicals useful as fuels or raw materials is given utmost importance in industrial process planning [46] [47]. The production of integrated circuits (IC) and chips involve a number of discrete steps which utilize hazardous or regulated solvents. Scientists at the Los Alamos National Laboratory, New Mexico, have developed a process that uses supercritical carbon dioxide in one of the steps of chip preparation and it significantly reduces the quantities of chemicals, energy and water needed to produce chips [48].

- Merck \& Co., Inc. and Codexis, Inc., both of USA, developed a second-generation green synthesis of sitagliptin, the active ingredient in Januvia ${ }^{\mathrm{TM}}$, a treatment for type 2 diabetes [49]. This collaboration lead to an enzymatic process that reduces waste, improves yield and safety and eliminates the need for a metal catalyst.

- Originally sold under the brand name of Zocor ${ }^{\circledR}$, the drug, simvastatin, is a leading prescription drug for treating high cholesterol. The traditional multistep procedure to make this medicine involve large amounts of hazardous chemicals and produced a large amount of toxic byproducts in its synthesis. Professor Yi Tang, of the University of California, LA, reported [50]. A synthesis of simvastatin using an engineered enzyme and a low-cost feedstock.

- NatureWorks LLC of Minnesota, USA, makes food containers from the polymer of polylactic acid sold in the market under the brand name of Ingeo ${ }^{\mathrm{TM}}$ [51]. The scientists at NatureWorks discovered a technique where microorganisms convert cornstarch into a resin that is just as strong as the rigid petroleum-based polymers currently used for making containers such as water bottles, mixing bowls etc. BASF is also marketing a fully biodegradable biopolymer Ecovio ${ }^{\circledR}$, prepared from petrochemical based Ecoflex ${ }^{\circledR}$ and polylactic acid obtained from maize starch [52].

- Traditional oil-based "alkyd" paints emits large amounts of volatile organic compounds (VOCs) as they get dried and cured imparting hazardous environmental impacts. Procter \& Gamble Co., and Cook Composites and Polymers, both of USA, through collaborative efforts created "Chempol MPS", a Sefose ${ }^{\circledR}$ oil (obtained from soya oil and sugar) — based alkyd resin that enables formulation of paints and coatings with significantly fewer volatile organic compounds (VOCs) than conventional, solvent-borne alkyd paints [53]. Subsequently, Sherwin-Williams Co., USA, developed water-based acrylic alkyd paints with low VOCs that can be made from recycled bottle plastics (PET), acrylics, and soybean oil. These paints combine the performance benefits of alkyds and low VOC content of acrylics [54].

\section{3. "Green" Fields in Synthesis and Industrial Processes}

1) Use of Alternative Feedstocks. There are already many new developments in this field, but the emphasis on 
renewable raw materials and a shift from fossil fuels is very desirable for sustainability. The starting materials for the chemical industry must be renewable and less toxic for workers and the environment [55].

2) Use of Less Hazardous Reagents. Presently, there are enough data for the toxicological and long term ecotoxicological properties of most of the chemicals used in academic institutes and industries [56]. Chemists and technologists must divert their efforts to use less dangerous raw materials and reagents for the synthetic routes of the production of chemical products. But if there are major obstacles they must choose less toxic substances and change their technologies accordingly. The systematic development and application of design rules for reduced hazard is one of the most important challenges facing green chemistry.

3) Ionic Liquids in Synthesis. Ionic liquids are used extensively in recent years as alternative solvents in organic synthesis. These substances are variously called liquid electrolytes, ionic melts, ionic fluids, fused salts, liquid salts or ionic glasses. Ionic liquids have many applications, as powerful solvents and electrically conducting fluids [57]-[59].

4) Synthesis in Water. Although water is considered a problem for organic synthesis since, especially, the purification and drying of final products are very cumbersome, in recent years water is considered as a good solvent for organic reactions. A good example is the Diels-Alder reactions in which the hydrophobic properties of some reagents make water an ideal solvent [60]. Water as a solvent accelerates some reactions because some reagents are not soluble and provides selectivity. The low solubility of oxygen is also an advantage for some reactions where metal catalysts are employed [61]-[65].

5) Synthesis in Perfluorinated Phases. In a newly developed methodology, chemists use perfluorinated biphasic solvents to dissolve catalysts with long perfuorinated chain. These catalysts can be very effective and provide high yields in some types of reactions where the catalysts play an important role. Another advantage is that after the reaction the catalyst can be separated and recycled [66] [67].

6) Supercritical Carbondioxide and Supercritical Water. A supercritical liquid is at a temperature and pressure above its critical point, where distinct liquid and gas phases do not exist. The supercritical liquid can effuse through solids like a gas, and dissolve materials like a liquid. In addition, close to the critical point, small changes in pressure or temperature result in large variation in density, allowing several properties of a supercritical fluid to be "fine-tuned". Supercritical liquids have been found to be suitable as a substitute for organic solvents in a large number of industrial and laboratory processes. Carbondioxide and water are the most commonly used supercritical fluids. In a wealth of scientific literature [68]-[70] supercritical $\mathrm{CO}_{2}$ and water are described as "green" solvents providing high yields and selectivities.

7) Organic Synthesis in Carbonic Esters. Carbonic esters, such as dimethyl carbonate $\left(\mathrm{CH}_{3} \mathrm{OCOOCH}_{3}, \mathrm{DMC}\right)$ are considered a new class of "green" solvents in many organic reaction processes. They can replace methylchlorides and dimethylsulphate esters which are very toxic and hazardous [71]. That DMC can be used in methylation reactions of phenols, anilines and carboxylic acids especially in presence of 1,8-diazabicyclo [5.4.0] undec-7-ene (DBU) for methylation of phenols, indoles and benzimidazoles have been established in a number of reports [72] [73].

8) Use of "Green" Catalysts. The area of catalysis is sometimes referred to as a "foundational pillar" of green chemistry [74]. It is thought that not only the "green" solvents will change the face of chemical reactions but also the use of "green catalysts" will improve substantially the effectiveness of many reactions and industrial processes. A true green catalyst offers little to zero toxicity to our environment. Use of green catalysts is, therefore, considered a keystone for innovative changes in chemical processes. Green catalysts affect energy use, reaction time, increase yields, reduce use of solvents and lower production of undesired by-products and wastes [75]-[77].

9) Replacement of Toxic Solvents with Lesser Toxic Ones. Through long past, process of replacement of toxic or hazardous organic solvents is still continuing. Success of this endeavor includes replacement of benzene with toluene, cyclohexane instead of carbon tetrachloride, dichloromethane instead of chloroform etc. The scientific literature contains many examples and practices with replacement of the most toxic and hazardous solvents [78] [79]. In fact, use of solvent affects a number of basic concepts of green chemistry and so, it is not astonishing that chemistry research towards the use of greener alternative solvents has grown enormously. If possible we should try to avoid using them and if needed, we should try to use harmless substances. In some case, particularly in the manufacture of bulk chemicals, it is possible to use no added solvent or so-called "solvent free" conditions. Though in some instances, including speciality and pharmaceutical products, a solvent is required to assist the process and transportation of substances. Alternative solvents suitable for green chemistry are those 
which have low toxicity, are easy to recycle, are inert and do not contaminate the products. The so-called green solvents have been used in diverse areas, for example, polymer chemistry, biocatalysis, nanochemistry, analytical chemistry etc. Truly, there is no perfect green solvent that can be applied to all situations and therefore, decisions have to be made. There are several ways in which organic solvents may be replaced, and a good argument can often be made for doing so on green chemistry grounds. However, it is important to remember that changing solvents may require additional energy (e.g. stronger heating), and organics may still be needed for work-up/ purification steps. A suggestive concise list of common solvents under the head of undesirable, usable and preferred is given below.

\begin{tabular}{|c|c|c|}
\hline Undesirable & Usable & Preferred \\
\hline $\begin{array}{l}\text { Pentane, hexane(s), di-isopropyl ether, } \\
\text { diethyl ether, dichloromethane, } \\
\text { dichloroethane, chloroform, DMF, NMP, } \\
\text { pyridine, DMA, acetonitrile, THF, dioxane, } \\
\text { DME, benzene, carbon tetrachloride etc. }\end{array}$ & $\begin{array}{l}\text { Cyclohexane, heptanes, toluene, } \\
\text { methylcyclohexane, methyl t-butyl ether, } \\
\text { isooctane, 2-methyl THF, cyclopentyl } \\
\text { methyl ether, xylenes, DMSO, acetic acid, } \\
\text { ethylene glycol etc. }\end{array}$ & $\begin{array}{l}\text { Water, acetone, ethanol, 2-propanol, } \\
\text { 1-propanol, ethyl acetate, isopropyl } \\
\text { acetate, methanol, methyl ethyl ketone, } \\
\text { 1-butanol, t-butanol etc. }\end{array}$ \\
\hline
\end{tabular}

10) Use of Microwave Heating in Synthesis. Use of microwave heating in synthetic chemistry has been started in 1986 [80] and its success with "green" criteria is well documented. By now, there are numerous research papers regarding green applications of microwave heating in synthetic chemistry illustrating high yields, without solvents, less reaction time and waste and very low energy consumption [81]-[83].

11) Use of Sonochemical Techniques for Synthesis. Sonochemical reactions by ultrasound waves are considered advanced green techniques. There are three classes of sonochemical reactions: homogeneous sonochemistry of liquids, heterogeneous sonochemistry of liquid-liquid or solid-liquid systems and overlapping with the previous techniques i.e., sonocatalysis. Ultrasonic protocol has beneficial applications in mixed phase synthesis, materials chemistry, biomedical uses etc. High yields, low energy requirements, low waste, no or very little use of solvents are some of the fundamental advantages of these sonochemical techniques [84]-[86].

12) Minimizing Energy Consumption. This is a very important objective considering the energy savings and the climatic change which has become a global environmental problem. The chemical industries have invested enough resources to reduce energy demands with innovations and changes in synthetic pathways. Green chemistry is interested to contribute through research to minimize energy consumption [87] in every step of the industrial process. For example an ammonia manufacturing unit in UK provides waste heat and carbondioxide both derived from fossil fuels to large commercial tomato greenhouses [88]. Making use of this waste resources, tomato growing seasons are extended, fuel consumption to heat greenhouses is reduced, air miles are saved by lowering imports and consumers are getting fresher produce (Figure 1).

13) Other Greener Protocols. In addition to the above methodologies advanced in the last few decades are techniques of biocatalysis, self-thermoregulated systems, soluble polymers, etc. Green chemistry covers all these aspects of eco-friendly methods and promotes their use in chemistry laboratories as well as in industrial synthetic processes [89] [90].

\section{Economic Ways towards Implementation of Green Chemistry: Instances From Some Developed Nations}

- Build a green chemistry (GC) and design for the environment (DfE) research and development fund. Establish a Government controlled grant fund to promote green chemistry research. Choose proposals in consultation with a higher education expert review panel. Other similar alternatives may include a green chemistry research challenge or public-private research joint venture. For example, The Green Chemistry Research Fund was identified as an option in Green Chemistry Options for the State of California. The California Green Chemistry Initiative (CGCI) [91] is a six-part initiative to diminish public and environmental exposure to toxins through improved knowledge and regulation of chemicals. Governments may also remodel existing programs to fund GC and DfE research e.g., New York Empire State Development offers financial support for projects that produce measurable outcome in pollution prevention, reuse and recycling [92].

- Provide green chemistry and design for the environment tax incentives. Maintain research and development efforts of companies attempting to develop and market safer, less toxic products through targeted tax breaks. For example, The Washington Business and Occupation Tax Incentive for High Technology is an annual 


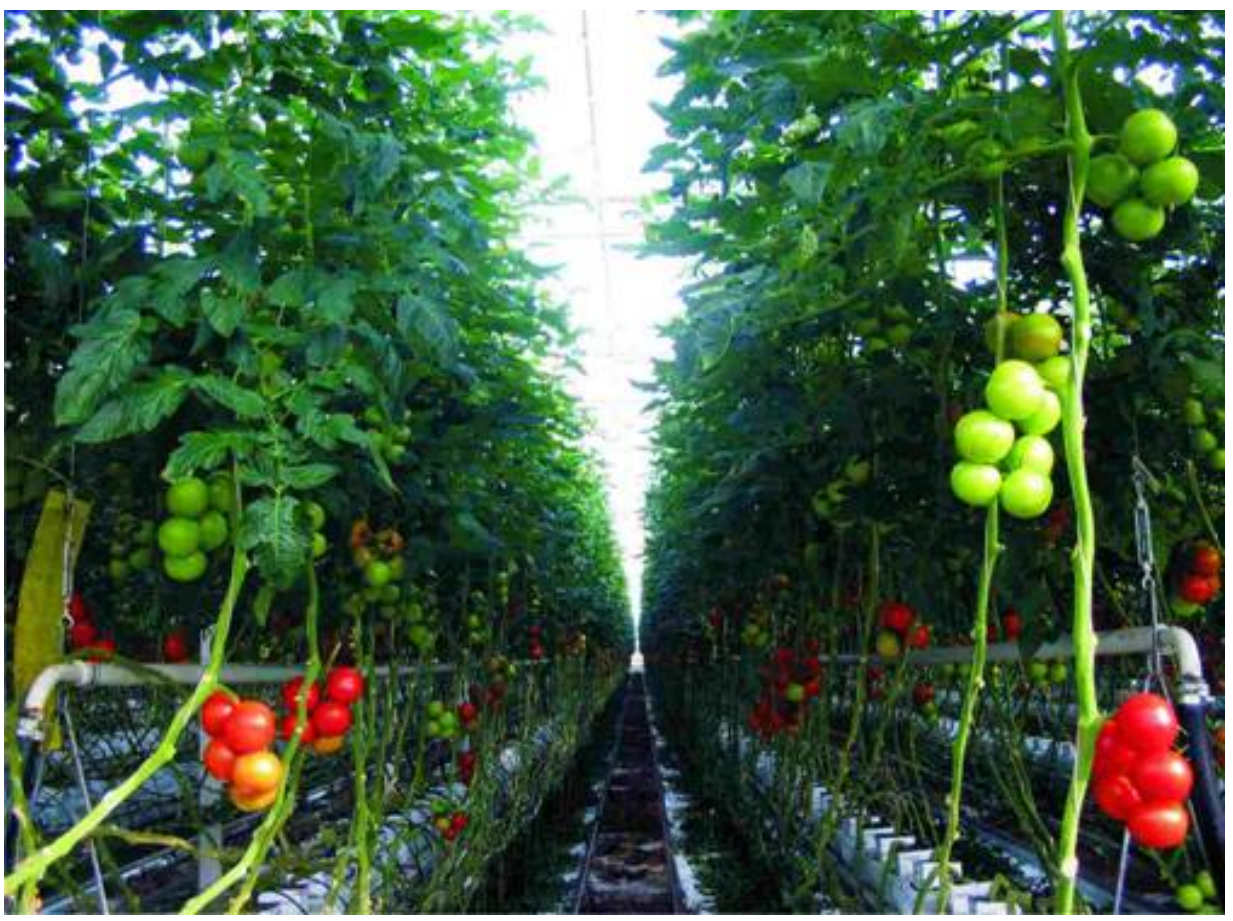

Figure 1. These tomatoes are growing in a greenhouse heated using waste steam from a nearby chemical plant making ammonia in UK. Waste carbondioxide from the plant is also used by injecting it into the greenhouse atmosphere to promote growth of the fruit (Image source [88]).

credit of up to \$2 million for research and development in specific high technology classes, including environmental technology [93].

- Make available investment tax credits, low-interest loans, loan guarantees or subsidies for green chemistry manufacturing equipments or products. Provide financial capital to companies at preferential terms through the means chosen to encourage GC and DfE. For examples, Green Chemistry Options for the State of California [94].

- Offer reduced-interest loans to businesses investments in the production of green products like France [95].

- Promote GC and DfE through industrial parks, brownfields (lands that are abandoned or underused and are potential site for redevelopment), or low-impact development. For example, The Modernizing Washington Manufacturers Program provides \$2 million for modernizing existing manufacturing processes, retaining jobs and converting them to "green" jobs through the existing Washington Manufacturing Services Fund [96].

\section{Developing World and Green Chemistry}

In the countries of developing world, the introduction of green chemistry is still in a stage of early-life even though it has significant need and endless scopes to play considerable role in these regions. Many of the practices in developing countries are still far from the conception of safety, pollution prevention and design of energy efficiency. Environmental pollution and waste management are some of the painful evils these countries are suffering from. Many of the reasons behind these problems lie in planning and course of action adopted that are based on end-of-pipe treatment, rather than prevention of pollution at source or implementing life cycle view in handling waste problems. Moreover, income generation activities are dependent on an efficient use of energy and other resources such as water and land which may pose some serious problems to future generations. Green chemistry could play a pivotal role in retrieving many of the problems of these nations starting from drinking water, energy and skilled man power insufficiency to atom economy, biodegradation and recycling of the wastes. Green chemistry can also have a very strong impact on water sufficiency issues particularly in that part of the developing world where water resources are polluted. It is through the implementation of a cleaner production and the use of safe and biodegradable chemicals that a huge volume of wastewater could be re-used to satisfy 
the emerging, critical need of water in many of these countries [97].

\subsection{Role of Academia}

The role of the academia is to bring about a mass understanding about the importance of green chemistry. They will make appropriate curricular instructions and write adequate learning resources. Colleges and universities can prepare students entering the workforce with the skills to help solve regional and global environmental issues. In addition, community education service may play an important role to educate the greater part of citizens on how they are relevant and germane to the environment protection and sustainability issues. The science and technology agencies of the country, responsible for funding of scientific activities must give adequate preference to the development of greener science and technology education and research. Recently, the German and Japanese Chemical Societies have assumed leadership roles in promoting green chemistry education within their own countries [98]. Educational initiative in green chemistry include textbooks, case studies, laboratory experiments, student organizations, summer schools, faculty training, secondary teacher training, resource tools, educational symposia and professional workshops [99] [100].

In short, educational institutions are crucial to advance the GC and DfE approaches by:

- Educating the future workforce of the green economy.

- Discovering new green chemistry and product options.

- Supporting efforts to overcome application challenges.

- Analyzing policy options.

- Serving as the common platform for needed dialogues between researchers and industries and businesses communities.

\subsection{Role of Industries}

Though it is true that many industries and research organizations are yet to implement the principles of green chemistry, nevertheless, some of them have begun to realize that the "think green" culture is more than just a fashion [101] [102]. Winds of changes have already started blowing and the more successful chemistry researchers and chemical technologists are opting eco-sustainable pathways especially in newly constructed process units. Industries in countries like India still need to make significant improvement from the environmental point of view. Most of the industrial R\&D section is mainly concerned with cost efficiency rather than ecofriendly processes. Though there has been some combined effort between academia and industries, still there is ample opportunity for increased partnership. There is immediate need for technology transfer from academic labs to industrial plants for meaningful application of green research. One of the big examples is the green approach of enzyme usage in various industries ranging from drugs to leather. The textile industry is one of the highly revenue generating industries in India and they are now switching over to microbial decolorization and degradation. So, a successful coordination between industry and academia may play an effective role to solve these problems in a greener way, obviously, without ubiquitous governmental red-tapism.

\subsection{Role of the Governments}

Government can take a lot of welfare steps for the cause of green chemistry by bringing and enforcing strict environmental legislations and by up-lifting the level of public awareness [103]. As in India, for example, one of the moderately recent and controversial instances of government initiative is the conversion of diesel-run automobiles to compressed natural gas-run ones in order to reduce air pollution. Moving of industries into industrial areas away from residential zones is another bold step taken by the Delhi government (recall the Special Economic Zone controversy). Besides, the governments are also emphasizing on new projects such as fuel pellets from municipal waste, aspirated H-cylinder engines for light commercial vehicles, meeting latest emission norms, battery-powered cars for pollution-free driving etc. The government should also increase funding to encourage research in green chemistry. By introducing green chemistry education at all levels, the governments can build a solid foundation toward green chemistry.

\section{Common Barriers to Implementation of Green Chemistry [104]-[106]}

- Absence of a "level playing field", i.e., the lack of global harmonization on regulation and environmental 
policy.

- Rigid notification and authorization processes which hinder new products and novel process development.

- The frequent need for speed and certainty of outcome caused by short-term planning perspectives.

- Burden of additional cost. Although green chemistry is often financially beneficial this is not invariably the case.

- Unsophisticated accounting practices which do not encompass total costs.

- The difficulty of obtaining research and development funding.

- Insufficient guidance on best practices of green chemistry.

- There are nations, industries and firms that are resistant to new technologies, or lack a culture that provides incentives for innovative activities—a kind of cultural barriers.

- Bureaucrats, in most of the cases, are not properly aware of green chemistry and green engineering and its potential benefits.

- Scientists and engineers who are needed to develop and implement green chemistry and green engineering, in cases, do not have the necessary and adequate background and training - a kind of workforce training barriers

- With many competitors, it may be difficult for financier to recover the cost of their investment, especially if there is a low value-add to their products. Network effects, monopolies and other market failures can also promote such market barriers.

\section{Expected Future}

If chemists are to fully embrace all facets of sustainable chemical processes, an exemplary shift in the way chemistry and engineering are taught and practised is required. Many challenges still lie ahead and the solutions will be found not only in the discipline of chemistry but also at its interfaces with engineering, physics and biology. More attention needs to be given to the whole manufacturing process and life cycle of both products and wastes. Only by combining the best ideas from the areas of science and technology the desired aim can be accomplished. Concepts such as renewable feedstock, atom economy, energy efficient reactions and eco-friendly solvents should be more prominent in basic chemistry education and there should be less emphasis on the very narrow concept of immediate product yield and end-of-pipe cleaning mind set. Obviously, there are plentiful future challenges to research in achieving green chemistry principles. In a nut shell, some of the challenges are:

- Use of water as an efficient source of energy.

- Improvement of environmentally benign solvent systems.

- Development of a synthetic methodology "toolbox" that is both atom economical and gentle to human health and our environment.

- Introduction of plastics and polymers properly designed for safe degradation through the use of additives-free design.

- Materials designed for recyclable/reusable/recoverable decisions based on implanted life cycle.

- Expansion of "preventative toxicology" where escalating knowledge of biology and environmental sciences act together continuously for designing new chemical produce.

- Enlargement of non-combustion, non-material intensive energy resources.

- Consumptive utilization of $\mathrm{CO}_{2}$ and other greenhouse gases with value-addition at high volume.

- Refinement of organic methodologies targeting diminished use of functional group protection/deprotection.

- Development of materials and especially, their surfaces, that are long-lasting, robust and do not require coatings/paints and cleaners.

\section{Conclusion}

In coming days, expansion of green chemistry needs to increase at an accelerated pace if molecular science is to meet challenges of sustainability. We need the relevant scientific, engineering educational and other communities to work together for sustainable future through green chemistry. In fact, the practice of a new kind of human ethics and the practice of green chemistry are virtually inseparable. It is commonly said that the revolution of one day becomes the new convention of the next. If the twelve principles of green chemistry are successfully incorporated as an integral part of everyday chemistry, there will no longer be a need for focusing, highlighting 
and renaming of green chemistry. And when that day comes, the challenges that chemistry will meet cannot be imagined. Furthermore, the success of green chemistry depends on the training and education of a new generation of chemists. Student at all levels have to be introduced to the philosophy and practice of green chemistry. Regarding the role of education in green chemistry, it is evident that the biggest challenge of green chemistry is to implement its rules in practice. In this context we can recall the famous saying of Albert Einstein "The significant problems we face today cannot be solved at the same level of thinking we were at when we created them".

\section{Note}

Several excellent examples of green chemistry may be found in the literature. This reference list is not meant to be all-inclusive, but includes a representative selection of green chemistry tools.

\section{References}

[1] http://www2.epa.gov/international-cooperation/international-priorities

[2] http://www.incaweb.org/inca/

[3] http://www.iupac.org/home/about/members-and-committees/divisions/iii/302/working-party-on-synthetic-pathways-an d-processes-in-green-chemistry.html

[4] http://www.acs.org/content/acs/en/greenchemistry.html

[5] http://www.oecd.org/env_sustainablechemistry_platform/

[6] Anastas, P.T. and Warner, J.C. (1998) Green Chemistry: Theory and Practice. Oxford University Press, Oxford.

[7] (a) http://www.epa.gov/greenchemistry/pubs/principles.html

(b) Anastas, P.T. and Zimmerman, J.B. (Eds.) (2012) Innovations in Green Chemistry and Green Engineering. Springer, Berlin.

[8] Trost, B.M. (1995) Atom Economy-A Challenge for Organic Synthesis: Homogeneous Catalysis Leads the Way, Angewandte Chemie International Edition, 34, 259. (The Concept of Atom Economy Was Developed by Prof. Trost of Stanford University, USA, in Recognition of Which He Received the US Presidential Green Chemistry Challenge Award in 1998.)

[9] Sato, K., Aoki, M. and Noyori, R.A. (1998) “Green” Route to Adipic Acid: Direct Oxidation of Cyclohexenes with 30 Percent Hydrogen Peroxide. Science, 281, 1646.

[10] http://www.2ndchance.info/fleas-spinosadGarden.pdf

[11] Bardley, D., Dyson, P. and Welton, T. (2000) Room Temperature Ionic Liquids. Chemical Reviews, 9, 18.

[12] Romano, U. and Garbassi, F. (2000) The Environmental Issue. A Challenge for New Generation Polyolefins. Pure and Applied Chemistry, 72, 1383-1388. http://dx.doi.org/10.1351/pac200072071383

[13] (a) Nicolas, N., Benvegnu, T. and Plusquellec, D. (2002) Surfactants from Renewable Resources. Actualite Chimique, 11-12, 70.

(b) Alonso, D.M., Bond, J.Q. and Dumesic, J.A. (2010) Catalytic Conversion of Biomass to Biofuels. Green Chemistry, 12, 1493-1513. http://dx.doi.org/10.1039/c004654j

[14] Stashenko, E.E., Puertas, A.M., Salgar, W., Delgado, W. and Martinez, J.R. (2000) Solid-Phase Microextraction with On-Fiber Derivatization Applied to the Analysis of Volatile Carbonyl Compounds. Journal of Chromatography A, 886, 175-182. http://dx.doi.org/10.1016/S0021-9673(00)00479-9

[15] Acardi, A., Bianchi, G., Di Giuseppe, S. and Marinelli, F. (2003) Gold Catalysis in the Reaction of 1,3-Dicarbonyls with Nucleophiles. Green Chemistry, 5, 64.

[16] Scott, G. (2000) “Green” Polymers. Polymer Degradation and Stability, 68, 1-7. http://dx.doi.org/10.1016/S0141-3910(99)00182-2

[17] http://www.verlagbt.de/verlag/ci/2009-05/themen4.en.php

[18] Workman Jr., J., Lavine, B., Chrisman, R. and Koch, M. (2011) Process Analytical Chemistry. Analytical Chemistry, 83, 4557-4578. http://dx.doi.org/10.1021/ac200974w

[19] Vanrolleghem, P.A. and Lee, D.S. (2003) On-Line Monitoring Equipment for Wastewater Treatment Processes: State of the Art. Water Science and Technology, 47, 1-34.

[20] Garrett, R.L. (1996) Pollution Prevention, Green Chemistry, and the Design of Safer Chemicals. In: DeVito, S.C. and Garrett, R.L., Eds., Designing Safer Chemicals: Green Chemistry for Pollution Prevention, American Chemical Soci- 
ety, Washington DC, Chapter 1, 2-15.

[21] DeVito, S.C. (1996) General Principles for the Design of Safer Chemicals: Toxicological Considerations for Chemists. In: DeVito, S.C. and Garrett, R.L., Eds., Designing Safer Chemicals: Green Chemistry for Pollution Prevention, American Chemical Society, Washington DC, Chapter 2, 16-59.

[22] Boethling, R.S. (1996) Designing Biodegradable Chemicals. In: DeVito, S.C. and Garrett, R.L., Eds., Designing Safer Chemicals: Green Chemistry for Pollution Prevention, American Chemical Society, Washington DC, Chapter 8, 156171.

[23] Tundo, P. and Selva, M. (2002) The Chemistry of Dimethyl Carbonate. Accounts of Chemical Research, 35, $706-716$. http://dx.doi.org/10.1021/ar010076f

[24] Tundo, P., Selva, M. and Memoli, S. (2000) Dimethylcarbonate as a Green Reagent. In: Anastas, P.T., Heine, L.G. and Williamson, T.C., Eds., Green Chemical Synthesses and Processes, American Chemical Society, Washington DC, 8799.

[25] Komiya, K., Fukuoka, S., Aminaka, M., Hasegawa, K., Hachiya, H., Okamoto, H., Watanabe, T., Yoneda, H., Fukawa, I. and Dozono, T. (1996) New Process for Producing Polycarbonate without Phosgene and Methylene Chloride. In: Anastas, P.T. and Williamson, T.C., Eds., Green Chemistry: Designing Chemistry for the Environment, American Chemical Society, Washington DC, Chapter 2, 20-32.

[26] PERP Programe-New Report Alert (2003) Nexant Inc. http://www.chemsystems.com/reports/search/docs/abstracts/0203-S8-abs.pdf

[27] Abad, A., Concepción, P., Corma, A. and García, H. (2005) A Collaborative Effect between Gold and a Support Induces the Selective Oxidation of Alcohols. Angewandte Chemie International Edition, 44, 4066-4069. http://dx.doi.org/10.1002/anie.200500382

[28] Enache, D.I., Edwards, J.K., Landon, P., Solsona-Espriu, B., Carley, A.F., Herzing, A.A., Watanabe, M., Kiely, C.J., Knight, D.W. and Hutchings, G.J. (2006) Solvent-Free Oxidation of Primary Alcohols to Aldehydes Using Au-Pd/ $\mathrm{TiO}_{2}$ Catalysts. Science, 311, 362-365. http://dx.doi.org/10.1126/science.1120560

[29] Ahluwalia, V.K. and Kidwai, M. (2004) New Trends in Green Chemistry. Kluwer Academic Publishers, Dordrecht/ Anamaya Publishers, New Delhi.

[30] http://www2.epa.gov/green-chemistry/presidential-green-chemistry-challenge-winners

[31] http://www.chemsystems.com/reports/search/docs/abstracts/0708_6_abs.pdf

[32] https://www.akzonobel.com/dissolvinegl/about_dissolvine_gl/

[33] Thompson, G.D., Dutton, R. and Sparks, T.C. (2000) Spinosad A Case Study: An Example from a Natural Products Discovery Programme. Pest Management Science, 56, 696-702.

[34] Salgado, V.L. (1998) Studies on the Mode of Action of Spinosad: Insect Symptoms and Physiological Correlates. Pesticide Biochemistry and Physiology, 60, 91-102. http://dx.doi.org/10.1006/pest.1998.2332

[35] Thompson, G.D., Michel, K.H., Yao, R.C., Mynderse, J.S., Mosburg, C.T., Worden, T.V., Chio, E.H., Sparks, T.C. and Hutchins, S.H. (1997) The Discovery of Saccharopolyspora spinosa and a New Class of Insect Control Products. Down to Earth, 52, 1-5.

[36] http://www.2ndchance.info/fleas-spinosadGarden.pdf

[37] https://outside.vermont.gov/agency/agriculture/vpac/Other\%20VPAC\%20Documents/Mosquito_Control/Larvicides/Sp inosad_products/Clark\%20Natular/23108Natular.pdf

[38] Samson, P.R., Bade, G.S. and Harris, W.J. (2010) Efficacy of Biocane ${ }^{\mathrm{TM}}$ against Southern One-Year Canegrub, Antitrogus consanguineus. Proceedings of the Australian Society of Sugar Cane Technology, 32, 50-61.

[39] http://tammi.tamu.edu/holtzapp2.pdf

[40] http://en.wikipedia.org/wiki/Bioconversion_of_biomass_to_mixed_alcohol_fuels

[41] Songa, H. and Lee, S.Y. (2006) Production of Succinic Acid by Bacterial Fermentation. Enzyme and Microbial Technology, 39, 352-361. http://dx.doi.org/10.1016/j.enzmictec.2005.11.043

[42] Pereira, C.S.M., Silva, V.M.T.M. and Rodrigues, A.E. (2011) Ethyl Lactate as a Solvent: Properties, Applications and Production Processes-A Review. Green Chemistry, 13, 2658-2671.

[43] Devi, A., Singhal, A. and Gupta, R. (2013) A Review on Spent Pickling Liquor. International Journal of Environmental Science, 4, 284-295.

[44] http://msdssearch.dow.com/PublishedLiteratureDOWCOM/dh_005c/0901b8038005c60e.pdf?filepath=surfactants/pdfs /noreg/119-02204.pdf\&fromPage=GetDoc

[45] Rojas, O.J., Stubenrauch, C., Lucia, L.A. and Habibi, Y. (2009) Interfacial Properties of Sugar Based Surfactants. In: 
Hayes, D.G., Kitamoto, D., Solaiman, D.K.Y. and Ashby, R.D., Eds., Bio-Based Surfactants and Detergents: Synthesis, Properties and Applications, AOCS Press, Urbana, 457-480.

[46] Scheirs, J. and Kaminsky, W. (2006) Feedstock Recycling and Pyrolysis of Waste Plastics: Converting Waste Plastics into Diesel and Other Fuels. John Wiley \& Sons Ltd., Chichester.

[47] (2009) Converting Waste Plastics into a Resource: Compendium of Technologies. United Nations Environmental Programme, Division of Technology, Industry and Economics, International Environmental Technology Centre, Osaka/ Shiga. http://www.unep.or.jp/Ietc/Publications/spc/WastePlasticsEST_Compendium.pdf

[48] Rubin, J.B., Davenhall, L.B., Taylor, C.M.V., Sivils, L.D., Pierce, T. and Tiefert, K. $\mathrm{CO}_{2}$-Based Supercritical Fluids as Replacements for Photoresist-Stripping Solvents.

http://pearl1.lanl.gov/external/c-cde/scf/pubs/images/la-ur-98-3855.pdf

[49] Hansen, K.B., Hsiao, Y., Xu, F., Rivera, N., Clausen, A., Kubryk, M., Krska, S., Rosner, T., Simmons, B., Balsells, J., Ikemoto, N., Sun, Y., Spindler, F., Malan, C., Grabowski, E.J.J. and Armstrong, J.D. (2009) Highly Efficient Asymmetric Synthesis of Sitagliptin. Journal of the American Chemical Society, 131, 8798-8804. http://dx.doi.org/10.1021/ja902462q

[50] Xie, X. and Tang, Y. (2007) Efficient Synthesis of Simvastatin by Use of Whole-Cell Biocatalysis. Applied and Environmental Microbiology, 73, 2054-2060.

[51] http://www.natureworksllc.com/ /media/News_and_Events/Press_Kit/NatureWorks-LLC-Background_pdf.pdf

[52] http://www.plasticsportal.net/wa/plasticsEU en GB/function/conversions:/publish/common/upload/biodegradable pla stics/Ecoflex_Brochure.pdf

[53] http://www2.epa.gov/green-chemistry/2009-designing-greener-chemicals-award

[54] http://www.sherwin-williams.com/home-builders/services/paint-technology-and-application/sw-article-pro-waterbased acryl.html

[55] http://www.acs.org/content/dam/acsorg/sustainability/acsandsustainability/sustainablemanufacturing/roadmaps/smrt-te chnology-area-1-alternative-feedstocks-pdf.pdf

[56] http://iuclid.eu/index.php?fuseaction=home.iuclidHome

[57] Welton, T. (1999) Room-Temperature Ionic Liquids: Solvents for Synthesis and Catalysis. Chemical Review, 99, 20712083. http://dx.doi.org/10.1021/cr980032t

[58] Earle, M.J. and Seddon, K.R. (2000) Ionic Liquids: Green Solvents for the Future. Pure and Applied Chemistry, 72 , 1391-1398. http://dx.doi.org/10.1351/pac200072071391

[59] (a) Laus, G., Bentivoglio, G., Schottenberger, H., Kahlenberg, V., Kopacka, H., Röder, T. and Sixta, H. (2005) Ionic Liquids: Current Developmemnts, Potential and Drawbacks for Industrial Applications. Lenzinger Berichte, 84, 71-85. (b) Cull, S.G., Holbrey, J.D., Vargas-Mora, V., Seddon, K.R. and Lye, G.J. (2000) Room-Temperature Ionic Liquids as Replacements for Organic Solvents in Multiphase Bioprocess Operations. Biotechnology and Bioengineering, 69, $227-$ 233.

[60] McKenzie, L.C., Huffman, L.M., Hutchison, J.E., Rogers, C.E., Goodwin, T.E. and Spessard, G.O. (2009) Greener Solutions for the Organic Chemistry Teaching Lab: Exploring the Advantages of Alternative Reaction Media. Journal of Chemical Education, 86, 488-493. http://dx.doi.org/10.1021/ed086p488

[61] Li, C.J. and Chen, L. (2006) Organic Chemistry in Water. Chemical Society Reviews, 35, 68-82. http://dx.doi.org/10.1039/b507207g

[62] Tsukinoki, T. and Tsuzuki, H. (2001) Organic Reaction in Water. Part 5. Novel Synthesis of Anilines by Zinc MetalMediated Chemoselective Reduction of Nitroarenes. Green Chemisdtry, 3, 37-38. http://dx.doi.org/10.1039/b008219h

[63] Li, C.J. and Chan, T.H. (1997) Organic Reactions in Aqueous Media. John Wiley \& Sons, New York.

[64] Grieco, P.A. (1998) Organic Synthesis in Water. Blackie Academic \& Professional, London. http://dx.doi.org/10.1007/978-94-011-4950-1

[65] Breslow, R. (1998) Water as a Solvent for Chemical Reactions. In: Anastas, P.T., Williamson, T.C., Eds., Green Chemistry: Frontiers in Benign Chemical Syntheses and Processes, Oxford University Press, New York, Chapter 13.

[66] Ritter, S.K. (2003) Designing Solvent Solutions: Novel Reaction Systems Combine Best Features of Homogeneous and Heterogeneous Catalysis. Chemical Engineering News, 81, 66-68.

[67] Bergbreiter, D.E. (2000) Polymer-Facilitated Biphasic Catalysis. In: Anastas, P.T., Heine, L.G. and Williamson, T.C., Eds., Green Chemical Synthesses and Processes, American Chemical Society, Washington DC, Chapter 15.

[68] Leitner, W. (2002) Supercritical Carbon Dioxide as a Green Reaction Medium for Catalysis. Accounts of Chemical Research, 35, 746-756. http://dx.doi.org/10.2116/analsci.22.1409 
[69] Sato, M., Ikushima, Y., Hatakeda, K. and Zhang, R. (2006) Applications of Environmentally Benign Supercritical Water to Organic Syntheses. Analytical Sciences, 22, 1409-1416. http://dx.doi.org/10.2116/analsci.22.1409

[70] Hâncu, D., Green, J. and Beckman, E.J. (2002) $\mathrm{H}_{2} \mathrm{O}$ in $\mathrm{CO}_{2}$ : Sustainable Production and Green Reactions. Accounts of Chemical Research, 35, 757-764. http://dx.doi.org/10.1021/ar010069r

[71] Ono, Y. (1996) Dimethyl Carbonate for Environmentally Benign Reactions. Pure and Applied Chemistry, 68, 367-375. http://dx.doi.org/10.1351/pac199668020367

[72] Shieh, W.C., Dell, S. and Repič, O. (2002) Nucleophilic Catalysis with 1,8-diazabicyclo[5.4.0]undec-7-ene (DBU) for the Esterification of Carboxylic Acids with Dimethyl Carbonate. The Journal of Organic Chemistry, 67, $188-2191$. http://dx.doi.org/10.1021/jo011036s

[73] Shieh, W.C., Dell, S. and Repič, O. (2001) Diazabicyclo[5.4.0]undec-7-ene (DBU) and Microwave-Accelerated Green Chemistry in Methylation of Phenols, Indoles, and Benzimidazoles with Dimethyl Carbonate. Organic Letters, 3, 2794281. http://dx.doi.org/10.1021/ol016949n

[74] Anastas, P.T., Kirchhoff, M.M. and Williamson, T.C. (2001) Catalysis as a Foundational Pillar of Green Chemistry. Applied Catalysis A: General, 22, 3-13.

[75] Sheldon, R.A. (2000) Atom Efficiency and Catalysis in Organic Synthesis. Pure and Applied Chemistry, 72, 12331246. http://dx.doi.org/10.1351/pac200072071233

[76] Reed, S. and Hutchison, J.E. (2000) Green Chemistry in Organic Teaching Laboratory: An Environmentally Benign Synthesis of Adipic Acid. Journal of Chemical Education, 77, 1627-1629. http://dx.doi.org/10.1021/ed077p1627

[77] Tanaka, K. and Toda, F. (2003) Solvent-Free Organic Synthesis. Wiley-VCH, New York. http://dx.doi.org/10.1002/3527601821

[78] DeSimone, J.M. (2002) Practical Approaches to Green Solvents. Science, 297, 799-803. http://dx.doi.org/10.1126/science.1069622

[79] (a) Sharman, J., Chin, B., Huibers, P.D., Garcia-Valls, R. and Hatton, T.A. (1998) Solvent Replacement for Green Processing. Environmental Health Perspectives, 106, 253-271.

(b) Sheldon, R.A. (2005) Green Solvents for Sustainable Organic Synthesis: State of the Art. Green Chemistry, 7, $267-$ 278. http://dx.doi.org/10.1039/b418069k

(c) Kerton, F.M. and Marriott, R. (2013) Alternative Solvents for Green Chemistry. 2nd Edition, RSC Green Chemistry No. 20, Royal Society of Chemistry.

[80] Gedye, R., Smith, F., Westaway, K., Ali, H., Baldisera, L., Laberge, L. and Rousell, J. (1986) The Use of Microwave Ovens for Rapid Organic Synthesis. Tetrahedron Letters, 27, 279-282. http://dx.doi.org/10.1016/S0040-4039(00)83996-9

[81] Lidström, P., Tierney, J., Wathey, B. and Westman, J. (2001) Microwave Assisted Organic Synthesis-A Review. Tetrahedron, 57, 9225-9283. http://dx.doi.org/10.1016/S0040-4020(01)00906-1

[82] Kappe, C.O. (2004) Controlled Microwave Heating in Modern Organic Synthesis. Angewandte Chemie International Edition, 43, 6250-6284. http://dx.doi.org/10.1002/anie.200400655

[83] Roberts, B.A. and Strauss, C.R. (2005) Toward Rapid, “Green”, Predictable Microwave-Assisted Synthesis. Accounts of Chemical Research, 38, 653-661. http://dx.doi.org/10.1021/ar040278m

[84] Price, G.J. (1992) Current Trends in Sonochemistry. Royal Society of Chemistry Publications, Cambridge.

[85] Cintas, P. and Luche, J.L. (1999) Green Chemistry: The Sonochemical Approach. Green Chemistry, 1, 115-125. http://dx.doi.org/10.1039/a900593e

[86] Cravotto, G. and Cintas, P. (2006) Power Ultrasound in Organic Synthesis: Moving Cavitational Chemistry from Academia to Innovative and Large-Scale Applications. Chemical Society Reviews, 35, 180-196. http://dx.doi.org/10.1039/b503848k

[87] http://www.acs.org/content/acs/en/greenchemistry/what-is-green-chemistry/principles/green-chemistry-principle--6.ht $\underline{\mathrm{ml}}$

[88] http://www.essentialchemicalindustry.org/processes/green-chemistry.html

[89] Alcalde, M., Ferrer, M., Plou, F.J. and Ballesteros, A. (2006) Environmental Biocatalysis: From Remediation with Enzymes to Novel Green Processes. Trends in Biotechnology, 24, 281-287. http://dx.doi.org/10.1016/j.tibtech.2006.04.002

[90] Bruggink, A., Straathof, A.J. and van der Wielen, L.A. (2003) A “Fine” Chemical Industry for Life Science Products: Green Solutions to Chemical Challenges. Advances in Biochemical Engineering/Biotechnology, 80, 69-113. http://dx.doi.org/10.1007/3-540-36782-9_3

[91] http://en.wikipedia.org/wiki/California_Green_Chemistry_Initiative 
[92] http://www.empire.state.ny.us/Manufacturing_\&_Environment/Environment/pollution_prevention.asp

[93] http://www.energy.wsu.edu/Documents/WSU\%20Green\%20Economy\%20FINAL\%20Report\%201-23-12\%20rev.pdf

[94] http://www.dtsc.ca.gov/PollutionPrevention/GreenChemistryInitiative/index.cfm

[95] http://europa.eu/rapid/press-release_IP-09-205_en.htm

[96] http://apps.leg.wa.gov/rcw/default.aspx?cite=24.50.010

[97] (a) Okonkwo, E.M., Okunola, O.J. and Ezeanyanaso, C.S. (2010) Sustainable Development: The Role of Chemical Technology in the Industrialization of Nigeria. Journal of Sustainable Development in Africa, 12, 135-146.

(b) Poliakoff, M., Fitzpatrick, J.M., Farren, T.R. and Anastas, P.T. (2002) Green Chemistry: Science and Politics of Change. Science, 297, 807-810. http://dx.doi.org/10.1126/science.297.5582.807

[98] Anastas, P.T. and Kirchhoff, M.M. (2002) Origins, Current Status, and Future Challenges of Green Chemistry. Accounts of Chemical Research, 35, 686-694. http://dx.doi.org/10.1021/ar010065m

[99] American Chemical Society (2002) Chemistry in the Community. W.H. Freeman and Company, New York, 372-375.

[100] Cann, M.C. and Connelly, M.E. (2000) Real-World Cases in Green Chemistry. American Chemical Society, Washington DC.

[101] Graedel, T.E. (1999) Green Chemistry in an Industrial Ecology Context. Green Chemistry, 1, 126-128.

[102] Fiksel, J. (2002) Sustainable Development through Industrial Ecology. In: Lankey, L.N. and Anastas, P.T., Eds., Advancing Sustainability through Green Chemistry and Engineering, American Chemical Society, Washington DC, Chapter 2, 13-29.

[103] Matus, K.J.M., Anastas, P.T., Clark, W.C. and Itameri-Kinter, K. (2007) Overcoming the Challenges to the Implementation of Green Chemistry. CID Working Paper No. 155, Center for International Development, Harvard University, Cambridge.

[104] Matus, K.J.M., Clark, W.C., Anastas, P.T. and Zimmerman, J.B. (2012) Barriers to the Implementation of Green Chemistry in the United States. Environmental Science Technology, 46, 10892-10899. http://dx.doi.org/10.1021/es3021777

[105] http://www.business-standard.com/content/b2b-chemicals/six-barriers-to-implementation-of-green-chemistry-in-india114010600785_1.html

[106] Matus, K.J.M., Xiao, X. and Zimmerman, J.B. (2012) Green Chemistry and Green Engineering in China: Drivers, Policies and Barriers to Innovation. Journal of Cleaner Production, 32, 193-203. http://dx.doi.org/10.1016/j.jclepro.2012.03.033 